\title{
RESEÑAS
}




\section{NUESTRIA HISTORIA: RAICES DEL PRESENTE. De Roux, R. Bogotá: Editorial Estudio, 1986.}

Con un nuevo enfoque histórico, en el cual los protagonistas dejan de ser los héroes legendarios y aparecen los pueblos, el profesor Rodolfo de Roux escribe este texto dirigido a estudiantes de 5o. grado de enseñanza básica primaria.

El libro comienza con la independencia explicada como un proceso que tiene sus causas y se inscribe dentro de un contexto que abarcaba el mundo occidental; la revolución norteamericana, la francesa, la industrial, la de los comuneros y para sus análisis tiene en cuenta no sólo las figuras de los héroes sino las necesidades económicas de la corona.

Desde el punto de vista didáctico la escritura amena y el estilo narrativo buscan interesar a los lectores y es por esto que seguidamente se presentan los derechos del hombre y del ciudadano y los derechos de los niños. En conclusión, la historia que presenta De Roux no es una sucesión ordenada de hechos: comporta un elemento vital, afectiva para el estudiante.

Para De Roux los gestores de la historia, son los pueblos y están conformados por hombres, mujeres y también niños. Dentro de las heroínas están las obreras que trabajaban en las fábricas de Medellín en 1920 y en todas las épocas ha habido niños soldados. El gamín también es un protagonista de nuestra historia, de violencia y abandono.

El resto de De Roux muestra por primera vez la verdadera dimensión de las guerras con sus componentes políticos, sociales y económicos. Además la guerra es actual: 9 de abril del 48, violencia de 1946 y 1957 y la guerra por la paz.

De Roux muestra a su vez las creaciones del pueblo colombiano: los logros de los procesos colonizadores, el trabajo del hombre en la construcción de infraestructura, la labor del obrero, del campesino y del estudiante nocturno. De Roux nos muestra una historia cercana, llena de fe y esperanza en el futuro, tal corno debe ser la actividad de los estudiantes que aprenden el país en nuestra historia. 